College of DuPage

DigitalCommons@COD

\title{
A Hybrid Genre Supports Hybrid Roles in Community-University Collaboration
}

Timothy Henningsen

College of DuPage, henningsent@cod.edu

Follow this and additional works at: https://dc.cod.edu/englishpub

Part of the English Language and Literature Commons

\section{Recommended Citation}

Henningsen, Timothy, "A Hybrid Genre Supports Hybrid Roles in Community-University Collaboration" (2010). Faculty Scholarship. 49.

https://dc.cod.edu/englishpub/49

This Book Chapter is brought to you for free and open access by the English at DigitalCommons@COD. It has been accepted for inclusion in Faculty Scholarship by an authorized administrator of DigitalCommons@COD. For more information, please contact orenick@cod.edu. 


\title{
A HYBRID GENRE SUPPORTS HYBRID ROLES IN COMMUNITY-UNIVERSITY COLLABORATION
}

\author{
Timothy Henningsen \\ Diane Chin \\ Ann Feldman \\ Caroline Gottschalk-Druschke \\ Tom Moss \\ Nadya Pittendrigh \\ Stephanie Turner Reich
}

This chapter describes how community-university collaboration is created by the Chicago Civic Leadership Certificate Program (CCLCP), an undergraduate program offered at the University of Illinois at Chicago (UIC). In CCLCP, partners from community-based, not-for-profit organizations mentor first- and second-year students who complete writing and research projects that their partner organizations need. In effect, then, CCLCP's community partners function as co-teachers, collaborating with university instructors to direct, monitor, and evaluate student work; this teaching relationship builds on a deeper and more interesting collaboration: the bilateral development of students' community-based projects.

Bilateral project planning engages community partners and classroom instructors in hybrid roles. When community partners come to see that research and writing intended to do public work can also fill the bill as an academic assignment, they begin to envision themselves as civic leaders who also are teachers. As classroom teachers re-imagine their students' academic work as forwarding the civic missions of our partner organizations, they begin to re-imagine themselves as teachers who also are civic actors. This rare "double vision" arises from CCLCP's collaborative planning process, and the center of gravity of our reciprocal planning process is a document we call the "partner project planner." The planner, we think, is an instance of a hybrid genre born from 
the fortunate conjugation of a traditional, syllabus-borne description of a class writing assignment and a project management tool commonly used to coordinate work in the professional and business worlds. Our planning document, we argue, provides a vehicle for pursuing the collaborative knowledge-making that creates valuable opportunities for student learning. We further argue that genre-defined as the dynamic nexus of individual agency, social structure, historical imagination, and everyday practice-plays a vital role in our enactment of communityuniversity collaboration.

\section{SOME NECESSARY BACKGROUND}

CCLCP is a four-course civic engagement program that selected students enter as incoming freshmen. High-school seniors who have been admitted to UIC hear about CCLCP in postal and electronic mailings soliciting applications for the program. Successful applicants are selected, not on the basis of their ACT scores or writing skill, but for their interest—a "spark," we call it—in exploring and addressing major social and civic issues and their willingness to work collaboratively. Over their first two years at UIC, our students take one CCLCP course each semester, earning four credit-hours for each course: the three credits normally attached to the course and an additional field research credit that recognizes the 30 hours each semester each student spends working on-site with his or her community partner organization.

During their first year, our students take CCLCP versions of UIC's two required writing courses. (Students who "test out" of the first writing course take the CCLCP version of a General Education rhetoric course in its place.) During their second year, CCLCP students take a specially designed version of a non-English department General Education course such as "Community Psychology" or "The Sociology of Youth." In the fourth and final CCLCP course, "English 375: Rhetoric and Public Life," students independently initiate community-based partnerships and complete projects with and for their partners; they also compile portfolios of their CCLCP work and produce résumés and cover letters aimed at securing internships. After receiving their civic leadership certificates, students may return to CCLCP as juniors and seniors to take part in our community-based, for-credit internship program.

We must pause in our discussion a little longer to explain a few basics about our university, our program, our writing philosophy and ourselves. The first task is to clarify the "we" who are writing this. No writing 
program administrator can "go public" on his or her own: it takes a team to extend the core principles of UIC's First-Year Writing Program into a community, or civic, context. The 2007-08 CCLCP team included the WPA and Director of CCLCP (Ann Feldman), the Assistant Director of CCLCP (Diane Chin), CCLCP Assessment Coordinator (Tom Moss), and the four Ph.D. students who that year designed CCLCP's first-year courses and initiated our collaborations with community partners: Timothy Henningsen, who took the lead on this essay; along with Caroline Gottschalk-Druschke; Nadya Pittendrigh; and Stephanie Turner Reich.

As mentioned at the outset, this essay chronicles the development of a document we call our "partner project planner"; we tweak the planner every year, but this essay will focus on the version used to prepare for the second CCLCP cohort of 39 students that entered UIC in fall 2007. During the previous spring and summer, we sought and initiated partnerships that would involve these incoming CCLCP students in the "communities of practice" (Wenger) of thirteen local, not-for-profit organizations. These partnerships would allow our students to become familiar with the inner workings of local organizations while learning about writing strategies and tactics. Each student's ultimate goal was to complete a written project-informed by both classroom lessons and community-based experience-that was needed by his or her community partner organization. We hoped that by moving from not-for-profit organizations to the classroom and back again, our students would see how rhetorically infused situations give rise to carefully crafted writingthat writing is not a random act driven only by creative genius. These community partnerships were designed to give our students valuable insights into the consequences of various genres of public writing as it occurs in and for Chicago not-for-profits. At the same time, the partnerships would enable non-profit organizations to meet some of their needs for written projects, to make connections with other non-profits and with UIC, and to receive a modest stipend for their efforts to mentor our students and teach them the ways of the not-for-profit world. Our program's emphasis on reciprocal partnership underscores our interest in the well-being and success of both students and partners, and demonstrates how the work of a writing program can, as the title of this book suggests, "go public."

CCLCP's attempt to build partnerships among teachers, community partner organizations, and students is rooted in the belief that all parties can and should collaborate to make knowledge. Indeed, we view 
collaborative partnership as an effective method of teaching writing (Feldman, et al.) In connecting the classroom with the community, we've learned much and our fundamental assumptions about teaching have been rigorously challenged, even changed. We would argue that teaching writing through community collaboration calls for a redirection of the ingrained impulses of both teacher and student, even as we negotiate, re-negotiate, and hybridize the shifting roles of our community partners and ourselves.

\section{LEAVING THE IVORY TOWER}

This book's title-Going Public-signals a turn from the vision of the university as an ivory tower, splendidly isolated from the larger community. This turn is especially relevant to UIC. The university was born in the wake of World War II, filling the educational needs of a burgeoning urban population, many of whom were returning GIs. When the U.S. Navy stopped training pilots on Chicago's Navy Pier, a new campus of the University of Illinois moved into the location that, jutting out more than half a mile into Lake Michigan, was connected to, but distinctly separate from, the city. Because, until then, there had been no public university in downtown Chicago, demand was incredibly high; after running out of room on the pier, Mayor Richard J. Daley in the early 1960s pushed for a new campus to be built on Chicago's historic Near West Side.

The reaction of those displaced by construction of the new campus was vigorous and widespread. Neighborhood residents felt the university was out to destroy their community; stories still swirl on campus of angry neighborhood business owners refusing to serve anyone associated with the new campus. The university did little to quell this anger, failing, in those early years, to develop a partnership with the community. Back when highways and railroad tracks served as distinct and wellrecognized boundaries among races, ethnicities, and social classes, the brick walls built to surround the U of I's new Chicago campus only exacerbated these divisions, leading to the campus's disparaging nickname, "Fortress Illini."

UIC has worked to change this perception, as best exemplified by the UIC Neighborhoods Initiative, which builds partnerships between the university and its surrounding communities as a means of strengthening both. The Neighborhoods Initiatives program is one actualization of the UIC's Great Cities Commitment to broadening and deepening the university's research agenda. The broader infrastructure offered by UIC's 
Great Cities Institute (GCI) includes a seed grant program for research built on community-university partnerships, a year-long faculty fellowship program, several urban policy research centers linked in various ways to UIC's College of Urban Planning and Public Affairs, support for invited researchers who take up residence at the Great Cities Institute, and a professional education initiative that offers on-line courses such as non-profit management. UIC's commitment to its urban context also has influenced the First-Year Writing Program and, subsequently, CCLCP. From its earliest years, UIC Neighborhoods Initiative offered support to the First-Year Writing Program by awarding the WPA, Ann M. Feldman, a seed grant to develop an individual partnership with a community organization (Feldman 2003) and, later, a year-long faculty fellowship to develop the theoretical and pragmatic underpinnings of the situated writing pedagogy of UIC's writing program. The director of the Great Cities Institute, David Perry, was centrally involved in the development of CCLCP and was a co-principal investigator on the grant from the federal Corporation for National and Community Service that allowed us to initiate CCLCP in 2004.

\section{SITUATED WRITING}

CCLCP's pedagogy grows from UIC's First-Year Writing Program, although "mainstream" writing classes do not depend on communitybased partnerships as CCLCP classes do. Those who teach first-year writing here talk about the "situated writing triad": a framework created by welding together genre theory, rhetoric, and social learning theory. We argue that all writing is situated in the social conditions that prompt it, and we believe that students take this axiom more seriously when an actual audience and a "real-life," complex social context are elements of the writing situation. We see genre awareness as shaping our students' writing, giving us the opportunity to connect our emphasis on social context and local situation to important concepts in genre theory. Not merely a taxonomy of "types" of writing, genre theory asks students to redirect the trajectory of their written inquiry from self to situation and/ or to the rhetorical conditions that constitute that situation (Bawarshi 153). Examples can be found in many of our genre-based writing assignments, especially those designed collaboratively by instructors and community partners, to which we'll return later.

Genre theory obviously relies heavily on rhetoric and rhetorical theory, which constitute the second element of our triad. As Michael 
Bernard-Donals and Richard R. Glejzer argue, rhetoric is best described as "the use of language to produce material effects in particular social conjunctures" (3). If social situations materialize through rhetoricwhich we feel they do-then we must direct our students to aim for awareness and understanding of the conditions that enable their own participation in, and influence on, social situations. Once they see and understand, students begin to think about their own possible participation in creating social change. When they consider the unique rhetoric employed in the genres of political speeches, manifestos, academic essays, and annual reports-to list a few examples of our in-class workstudents gain access to the powerful histories that often go hand-in-hand with certain words or phrases; knowing these histories helps our wouldbe writers realize the motives and consequences of language when it is wielded as an agent of change.

And finally, given the "public" nature of both genre theory and rhetoric, our pedagogy requires an emphasis on social learning theory. Our notion of social learning is based on the work of Etienne Wenger, who argues that practice, which he defines as the interaction of social entities, is both "a process by which we can experience the world and our engagement with it as meaningful" (51) and a "shared history of learning that requires some catching up for joining" (102). Quite simply, learning takes place through social engagement and of course, through doing. And so, in CCLCP, we ask our students to engage in the social situations of our partners, which emerge from life in urban Chicago. Pedagogically speaking, we echo Wenger when he argues that "learning cannot be designed; it can only be designed for" (229; italics in original), which helps explain our insistence that collaborative knowledge-making requires the ability not only to design well-informed plans, but also to roll with the punches when those plans are disrupted and must change, as they so often do. In other words, student learning is often beyond our control; the more we, as CCLCP instructors, recognize this, the better the collaborative experience for all involved. In sum, because our pedagogy thrives upon social situations, both within and beyond classroom walls, we seek to make those walls as porous as possible.

\section{INITIATING PARTNERSHIPS}

Partnerships aren't born: they are made. In spring and summer 2007, we began recruiting partners by inviting the return to CCLCP of some of the organizations with which we had partnered while working with our 
first cohort of students, from fall 2004 through spring 2007. (In its original incarnation, CCLCP was a three-year program.) A larger and more diverse range of partnerships was needed to satisfy the second cohort's larger number of students and various interests, so we looked for prospective partners whose missions addressed urban challenges or offered programs intended to improve the quality of urban life. Of course, we considered organizations that the CCLCP instructors had connections to or interests in, given our team's variety of civic, activist, and rhetorical engagements. And, as we had in 2004, we drew on our ongoing relationship with UIC Neighborhoods Initiatives.

After we'd created a list of potential partner organizations, the assistant director of CCLCP, Diane Chin, sent a Request for Proposal (RFP) to the community-based, not-for-profit organizations that had not previously partnered with us. (Partners who had worked with the previous cohort and with whom we wished to continue a relationship were simply invited back.) Our RFP explains not only the nature of CCLCP, but also the benefits and responsibilities of a CCLCP partnership. Because we differ very significantly from volunteer and/or internship programs (programs with which most partners already are quite familiar), the RFP is the crucial first step in acquainting new partners with the structural and philosophical features of CCLCP. The RFP encourages potential partners to "identify student projects that serve both learning goals and our partners' missions" in order to emphasize the program's dual interest in academics and community engagement. After an appropriate interval, Diane contacted potential partners by phone for a series of very important conversations. These calls gave prospective partners not only an opportunity to ask questions, but also a platform for discussing writing projects that might help fill their organizations' needs. These conversations also gave us the chance to see if the organization's staff was receptive to-and could make time for-engaging with our students as co-teachers and mentors.

Responses to the RFPs were reviewed by CCLCP's teaching staff, director, and assistant director. Organizations accepted into partnerships were invited to a mid-summer orientation and project planning event that launched both the new and continuing partnerships for the school year ahead. This event included a dinner followed by a planning workshop, at which CCLCP administrators and instructors and representatives of our partner organizations got to know each other and began to brainstorm student projects. After this session, instructors, armed 
with our partner project planner, then visited the partners' community sites to work individually with partners on developing the projects students would complete during the coming semester. (We'll say more about this process in a moment.) The project development process was completed a few weeks into the fall semester. Then, after students and partners were matched, the assistant director prepared and sent to each partner a formal UIC Memorandum of Understanding (MOU) or, in some cases, a formal Board of Trustees-approved contract, that officially acknowledged the collaborative effort and set out the terms of the $\$ 450$ per-student stipend to be paid to each partner at the end of each semester "for services rendered to CCLCP students."

\section{HOW A HYBRID GENRE CREATES A SITE FOR ACTION}

On the most obvious level, the partner project planner, which we include below, is an instance of a hybrid genre derived from mating UIC's FirstYear Writing Program assignment prompts with professional project management documents. What is much more interesting, though, is the living source of this hybridity: the diverse, even incongruous, communities that come together through this genre to collaborate on writing projects and, what is more important, to participate in social change. The notion of the hybrid genre emerges from the work of Mikhail Bakhtin and, in particular, his famous essay on speech genres (1986). In this essay, he argues for the situatedness of genre and how every speech act occurs with a sense of the consequences that will emerge. This work on speech genres evolved, carrying with it earlier themes of answerability, in which all subjects must become authors who participate in the forceful energy that genres emit (1993). This rich sense of genre as a "form of life" and as a frame for social action (Bazerman 1997, 19) has informed contemporary composition studies as evidenced in such edited volumes as Schroeder, Fox and Bizzell's Alt Dis (2002) and John Trimbur's Popular Literacy (2000) that examine the varied and situated roles of discourse.

CCLCP's partner project planner emerged to solve a very real problem and to respond to something of a role reversal. (The partner planner is Figure 1 in the appendix.) Our instructors, who were accustomed to setting up classroom-based writing projects, needed to coordinate with our community partners to envision the nature of students' community-based projects. And, on the other hand, the community partners, who knew exactly what sort of projects their organizations 
needed, had no easy way of communicating this need to students or their instructors.

Things grew even more complicated with the cohort starting in fall 2007 because two new structural features of our program required that we develop our partnership relationships differently than we had in the past. First, in fall semester, we offered the incoming cohort two CCLCP classes: English 160, the first required writing course, and English 122, a rhetoric course that carries General Education credit for students who had "tested out" of English 160. Second, to give students more and more varied choices, we had recruited twice the number of partners as in previous years. But how could we give all CCLCP students a choice of partners and projects if certain partners were "attached" only to a certain class? Our administrative solution was to uncouple the role of instructor and the role of partner liaison. Until the advent of our second cohort, instructors taught a single group of students and worked with a single group of partners to develop projects for those same students. Now, each of our instructors would play two distinct roles: each would co-teach a section of either English 160 or English 122 and, in that role, be responsible for the students enrolled in that particular class. But, besides being a "classroom teacher," each instructor also would act as a "partner liaison" by developing, collaboratively, a project or set of projects with three or four of the community partners who had come on board with CCLCP. These partner relationships-at the insistence of the instructors-crossed classroom boundaries. That is, students could choose from the full range of civic missions represented by the thirteen partners, and partners would find themselves working with some students enrolled in English 160 and others enrolled in English 122. With this important structural change, instructors' role identities began to depend on shifting situations — they flexed between serving as classroom instructors and partner liaisons. This is where the collaboration begat hybridity; suddenly Timothy, Caroline, Nadya, and Stephanie were not "just" teachers of writing.

In their role as liaisons between partners and students, the "CCLCP Four" needed a tool to facilitate their collaborative work with partners by clearly defining the projects their students would produce. This tool, born of necessity, is the "partner project planner." And, as we look back at our creation of this worksheet-like document, we realize the extent to which current work in genre theory, rhetoric, and social learning theory contributed to its development. The partner project planner illustrates 
how situated writing stems from and responds to the demands of collaboration. Instructors, on the one hand, had planned a course curriculum that they hoped would bring students into their partners' communities of practice and prepare them to undertake the projects needed by their partner organizations. (We describe this curriculum briefly below.) Each partner, on the other hand, needed a particular project but didn't have time to extensively tutor each student on how that project should be imagined, designed, completed, and delivered.

The partner project planner turned out to be an example of a "hybrid genre," as it had to be if it were to meet the needs of both community partner organizations and students in unique ways. For students, the partner project was the culminating work of their course. All previous course projects, which incrementally prepared students for the final one, had been assigned using a version of the assignment template that is routinely used in the First-Year Writing Program at UIC. This information-packed template reflects our commitment to situated writing as expressed in four key terms: situation, genre, language, and consequences (see Feldman, Downs, and McManus 2005). The standard classroom writing project template consists of eight sections, each elaborated with the appropriate information: the title of the writing project; a list of resources students may choose to use; due dates and length; detailed descriptions of the writing situation, the specific task, the genre, and the potential consequences of the piece of writing; and evaluation criteria. This classroom document can speak through a shorthand of sorts because, from their first days in the English 160 classroom, students learn the meaning of situation, genre, language, and consequences, or more commonly, SGLC. These terms were familiar to our instructors, of course, but entirely unfamiliar to our community partners and so not very useful.

Our partners had an entirely different orientation to the muchneeded projects that were to be completed by our students. Their role in CCLCP was not to teach writing, but the context from which writing would emerge; their job was to integrate students into the community of practice of their organizations so that student projects could succeed. To create effective projects, students needed to know how knowledge was made in their partner organizations and how the culture of their partner organizations defined and governed daily work. (Of course, working with CCLCP students was a minute portion of the community partner's monumental daily responsibility.) Our assistant director, Diane 
Chin, knew from her previous work with not-for-profits that the partner project planner must function as a two-way bridge, connecting students and teachers with the specific and unique context and culture of the not-for-profit organization and connecting community partners with the concepts to which writing teachers expose their students. In earlier years of her career, Diane had created similar documents as a way of communicating to her staff what the C.E.O. of her organization wanted a specific project to accomplish. In more recent times, Diane had taught firstyear writing at UIC. These experiences gave her a grasp of both worlds' vocabularies and concerns that enabled her to create a lingua franca for our project planner. Once intensive, individualized planning had taken place on the bridge between instructor and partner, the students needed to enter this collaborative terrain: the partner project planner would become their road map. Here is another example-or perhaps a consequence-of hybridity: the planner is not only the offspring of two genres, but also fills the roles of both bridge and map.

And more hybridity: once completed, the planner served as a communication tool between instructors and partners, the basis for a contract between the community organization and the university, and a guide for students.

The fall 2007 planners explicate an arresting variety of projects. One partner organization, whose partner planner we include at the end of this chapter, focuses on collecting and sharing oral histories of immigrants; this partner wanted to compile the "success stories" of their service consumers in a booklet and needed a CCLCP student to write promotional material for the book's launch. Another partner needed CCLCP students to write articles for a bilingual newsletter to be distributed to parents of elementary-age students at a community school. An activist organization that works with the majority Latino/a population of a neighborhood near UIC wanted ideas for drawing residents into involvement with community causes, ideas which would be presented in a student-written report to its advisory board. Other planners call for sections of annual reports, marketing materials, and museum display text. Despite this variety, every project depended upon ongoing conversations between instructor-as-liaison and the community partner, and each was an attempt to create, as the RFP explained, "projects that serve both learning goals and our partners' missions."

Although, in all cases, the most intense bursts of teacher/partner collaboration occurred while completing the project planners, it's safe 
to say that the process was different with each of our thirteen partners. Some partners made it easy by responding to the prompts included in the planners with such clarity and detail that their project planners were virtually ready to hand over to students with little instructor input. Others needed a good deal of prodding just to return phone calls, which is not surprising, given the hectic environment of most not-forprofits. Some partners, because of changing organizational needs and resources, modified their project planners mid-semester, presenting another challenge-one familiar to those working outside the classroom-to both instructor/liaisons and students. The creation of the project planner often became easier when our instructor/liaisons asked partners to identify an example of the genre in which they wanted students to work; for some organizations, however, this was impossible, as they wanted students to create a document that they badly needed primarily because nothing like it existed.

\section{CLASSROOM PREPARATION FOR PARTNER PROJECTS}

Instructor/liaisons began meeting with community partners over the project planners in late summer 2007, just after an orientation dinner at which partners learned about CCLCP and the crucial importance of their roles as mentors and co-teachers. The dinner meeting launched collaborative knowledge-making by enabling partners and CCLCP staff to bounce around ideas for approaching their partnerships. Using the partner project planners as a basis for brainstorming and discussion, partners described projects they needed and considered whether they were feasible. Instructors explained how the academic curriculum helped prepare students for engagement with partner organizations' communities of practice. Figure 2, included in the appendix, offers an outline of the five assignments required for English 160 and English 122, and the CCLCP "calendar" illustrates the integration of classroom and community activities.

Students began fall semester by writing a manifesto. This writing project prompted students to identify the social or civic issues that mattered most to them. Besides fostering student thinking about current issues, the manifesto has several virtues as a writing assignment. To create this document-a very public declaration of the writer's stand on a particular issue or cluster of issues-a student must rely on a keen awareness of audience, social context, and language. Instructors hoped this assignment would prepare students to identify partners with similar 
interests and agendas at the "Partnership Fair" set for the second week of the semester. Also before the fair, students were assigned to independently research several of the thirteen partner organizations that most attracted them. The fair was an exciting event, full of buzz: partners set up booths in the Residents Dining Hall of Jane Addams Hull-House, which graces the east border of UIC's campus, and students circulated among them, asking questions about the work of their organizations, and learning about projects partners needed. We had hoped to have the partner project planners complete by the Partnership Fair but not all were; even so, the fair was a great success. An unexpected but most welcome synergy had occurred, and both students and partners were charged up for the semester ahead. Two days after the Partnership Fair, the classes met jointly, so students could match themselves to community partners through a process fondly referred to as "the land grab." Poster-size sheets, each listing a partner organization and the number of student positions available there, were displayed around the room; students were instructed to stand ("walk, don't run" was the mantra) in front of the poster naming the partner with which they most wanted to work. The students were responsible for resolving disputes among themselves through the use of their budding powers of persuasion. We realized this student-driven process bore some risk, but thought it was the best way to encourage students to "own" their new partnerships. (We are pleased to report all student competition for partnerships was peacefully and cheerfully resolved, albeit, in a few cases, through the device of "rock-paper-scissors.")

Next, students were assigned to introduce themselves to their new partners in a professional e-mail describing their skills, interests, and experience. This was the first step toward "handing students the keys to the car" - a metaphor for the self-responsibility and leadership so important to CCLCP. The next project-due some time after students became generally familiar with their partners-was a community strengths profile. Creating this assignment had been tricky; only one of our instructors had experience writing a community strengths profile, and so the project was included with some hesitation. The community strengths profile required students to immerse themselves in the communities that their partners served and develop their skills at writing a complete profile from field notes. The focus on community strengths, rather than deficits, was intended to help students see how their partner communities could springboard from existing strengths 
to positive change. We also wanted students to resist the news media's clichéd focus on poverty, helplessness, and hopelessness. The students were required to read a model of the genre, but had to rely on their own observations and analyses when crafting their strength assessments. The fourth genre-based assignment leading up to the final project-the much-planned-for community partner project-was an interview and written summary; students interviewed their contact person at their community partner organization to garner information that would enhance their understandings of their partner projects. The interview and focused summary assignment gave students an important opportunity to craft questions and discuss with their partners what they needed to do to make their projects successful. When our students turned in their interview assignments, we were pleased to discover that this activity really did help them understand their community partner organizations' missions and the role of their final writing project in advancing those missions.

By mid-term, collaboration took on a new form and came to include a new partner: the student. Although intensive planning between instructor/liaisons and partner/teachers had initiated the collaboration, the CCLCP student soon became the key player. Aside from occasional check-ins, the instructor-partner relationship moved to the back burner unless difficulties arose. Most of the instructor-partner conversations that occurred after students began working with their community partner organizations were sparked by student or partner scheduling problems and occasional misunderstandings. In an end-ofsemester focus group, one partner lamented that there was no mechanism for sustaining the collaborative nature of the early brainstorming sessions that began at the July dinner and continued during the individual partner-instructor meetings that followed. In response, CCLCP has begun to consider sponsoring end-of-semester partner-student colloquia for our second-year classes so partners can continue to participate in conversations about the issues that drive their organizations.

\section{WHAT IT MEANS WHEN WRITING INSTRUCTION GOES PUBLIC}

The result of our particular instance of a hybrid genre, the partner planning document is, of course, a student project, which we hope the community partner can use. We include in Figure 3 (see appendix) an example of a project planner created collaboratively in fall 2007 by Margot Nikitas of the Jane Addams Hull-House Museum and Caroline 
Gottschalk-Druschke of CCLCP. This document provided a road map for Carla Navoa, then a CCLCP first-year student, who would develop a promotional flyer for a forthcoming book called Chicago: An Immigrant City.

What did Carla have to learn in the writing classroom and at the HullHouse Museum to complete this project? How did these diverse understandings come together in Carla's mind and work successfully to achieve the project's purpose? Richard Lanham argues in his recent book, The Economics of Attention: Style and Substance in the Age of Information, that the answers to these questions largely depend on where we focus our attention. The arts and letters, as well as rhetoric, he claims, are "wholly occupied with creating attention structures" (21), which simply means directing awareness (26). Lanham reminds us, though, that Kenneth Burke was fond of saying that "Every way of seeing is a way of not seeing" (164): paying attention over here means you cannot pay attention over there. And each new element that we focus on is in some way changed by our attentive gaze.

Framing our classrooms and our partner organizations as "communities of practice" redirects our attention and so changes the way we understand them. Our student, Carla, had to learn that producing a flyer was not simply a translational activity. She was, as we said earlier, "using language to produce material effects" in a very particular situation (Bernard-Donals and Glejzer, 3). She was taking action, not simply producing sequences of words. Carla was surrounded by genre: manifestos, e-mails, partner project planners, promotional flyers. All of these she needed to understand materially because they were connected to actions, to steps taken, to visions imagined and realized, and to missions hoped for and accomplished. The partner project planner, which Carla received soon after choosing to work with Margot Nikitas at the Jane Addams Hull-House Museum, targeted the creation of an effective promotional document. To hit the bull's-eye, Carla needed to reconsider classroom lessons in ethos, pathos, logos, and kairos, as well as lessons in situation, genre, language, and consequences. In thinking about her partner organization as a community of practice, she had to use her on-the-ground knowledge of the Hull-House Museum and what makes it tick every day. In conversations with Margot, Carla learned why the planned book is important and what problems and issues the HullHouse staff were hoping the book would address. She learned through engagement and connection, rather than through the reified practices that so often pass for education. And most important of all, Carla had 
to imagine what work this book would do, what conditions it would change, what narrative about Chicago's immigrant population-a population that Hull-House has served throughout its history and will serve in the future-it could rewrite.

The project planner, a small and seemingly insignificant tool of both writing assignment-making and project management, functioned as a dynamic point of contact for the knowledge-making activities that contributed to CCLCP's partnership with the Hull-House Museum and with the many other organizations we worked with during one memorable semester. Working with the planning document taught us that genre, rhetoric, collaboration, and reciprocity constitute the glue that holds CCLCP together. It also taught us that collaboration doesn't always proceed as planned. Collaboration is typically more complicated than one might expect simply because of differences in the co-planners' objectives. Partners' goals for students naturally center on producing work that benefits the partner organizations, while instructors' goals for students naturally center on enhancing the teaching and learning of course matter. While all this is as it should be, the difference in perspective produces tensions that sometimes show up-albeit very politelyin planning sessions and in periodic check-in conversations involving instructors and partners. We've learned that this tension is a good thing because it sparks creativity in planning and executing projects. In this sense, partner-instructor differences can become highly productive once they're accepted as a natural part of the process; so all the lessons about genre, rhetoric, collaboration, and reciprocity learned by students in our program are institutional lessons as well. Going public and engaging with community partners in ways that benefit everyone concerned can present challenges, but we make significant new knowledge when we find ways to understand and overcome those challenges.

While WPAs typically concern themselves with the writing that students do, our work with CCLCP has challenged us to coordinate engagement and reciprocity on many levels, administrative and contractual as well as cultural and linguistic. We carried our genre-based work with the partner project planner in 2007-08 forward into the second year of our two-year program and onto entirely new terrain as we coached two faculty members, both new to CCLCP, who were to teach specially designed CCLCP sections of community psychology and the sociology of youth. Here we saw once again the challenge of hybrid roles as discipline-based faculty attempted to integrate their particular approaches 
to the social sciences into the unique projects needed by community partners. In their final course, English 375, CCLCP students will identify their own partners and develop proposals for their own projects; they will assume the hybrid role of student-project manager. And finally, as juniors and seniors, these students will have an opportunity to receive credit for writing and research internships with community partners of their choice. Our goal in CCLCP is nothing less than changing our institution's culture. One proper goal of an urban public research university such as UIC, is to make knowledge in partnership with others in its metropolitan area. CCLCP's aim is for our colleagues-both faculty and administrators - to see writing instruction not only as preparation for upper-level classes but also as a way to contribute to our university's knowledge-making activities. By doing precisely that, the writing activities of CCLCP students parallel the writing activities of faculty, and these public efforts focus our attention on writing's situatedness and, most important, its consequences.

\section{REFERENCES}

Bakhtin, M. M. 1993. Toward a philosophy of the act. Trans. Vadim Liapunov. ed. Vadim Liapunov and Michael Holquist. Austin: U of Texas P.

Bakhtin, M. M. 1986. The problem of speech genres. Speech genres and other late essays. Trans. Vern W. McGee. ed. Caryl Emerson and Michael Holquist, 60-102. Austin: U of Texas P.

Bawarshi, Anis. 2003. Genre E् the invention of the writer: Reconsidering the place of invention in composition. Logan: Utah State UP.

Bazerman, Charles. 1997. The life of genre, the life in the classroom. In Genre and writing: issues, arguments, alternatives, ed. Wendy Bishop and Hans Ostrom, 19-26. Portsmouth, NH: Boytnon/Cook.

Bernard-Donals, Michael, and Richard R. Glejzer. 1998. Introduction. Rhetoric in an antifoundational world: language, culture, and pedagogy. ed. Michael Bernard-Donals and Richard R. Glejzer,1-30. New Haven: Yale UP.

Bringle, Robert G., Richard Games and Edward A. Malloy. 1999. Colleges and universities as citizens. Needham Heights, MA: Allyn and Bacon.

Brukardt, Mary Jane, et al. 2004. Calling the question: Is higher education ready to commit to community engagement? Wingspread Conference, Institutionalizing University Engagement, 18-19 Apr. 2004. Milwaukee: Milwaukee Idea Office, University of Wisconsin-Milwaukee.

Burke, Kenneth. 1950, 1962. A rhetoric of motives. Berkeley, CA: University of California Press.

Chin, Diane, et al. 2006. Strong at the seams: Joining academic and civic interests. In Quick hints for educating citizens, ed. James L. Perry and Steven G. Jones, 5-6. Bloomington: Indiana UP.

Feldman, Ann M. 2008. Making writing matter: Composition in the engaged university. Albany: State U of New York P.

Feldman, Ann M. 2003. Teaching writing in a context of partnership. In City Comp: Identities, Spaces, Practices, ed. Bruce McComiskey and Cynthia Ryan, 203-215. Albany: State U of New York P.

Feldman, Ann M., Ellen McManus and Nancy Downs. 2005. In Context: Reading and Writing in Cultural Conversations. 2nd ed. New York: Pearson/Longman. 
Feldman, Ann M., et al. 2006. The impact of partnership-centered, community-based learning on first-year students' academic research papers. Michigan Journal of Community Service Learning 13(1): 16-29.

Gibbons, Michael, et al. 1994. The new production of knowledge: The dynamics of science and research in contemporary societies. London: Sage.

Holland, Barbara A. 2000. Institutional impacts and organizational issues related to service learning. Michigan Journal of Community Service Learning Fall: 52-60.

Lanham, Richard A. 2006. The economics of attention: Style and substance in the age of information. Chicago: U of Chicago P.

Maurrasse, David J. 2001. Beyond the campus: How colleges and universities form partnerships with their communities. New York: Routledge.

Schroeder, Christopher, Helen Fox and Patricia Bizzell. 2002. Alt dis: Alternative discourses and the academy. Portsmouth, NH: Boynton/Cook Heinemann.

Trimbur, John. 2001. Popular literacy: Studies in cultural practices and poetics. Pittsburgh: U of Pittsburgh P.

Walshok, Mary Lindenstein. 1995. Knowledge without boundaries: What America's research universities can do for the economy, the workplace, and the community. San Francisco: Jossey-Bass.

Wenger, Etienne. 1998. Communities of practice: Learning, meaning, and identity. Cambridge: Cambridge UP. 


\section{APPENDIX 1}

\section{CCLCP Partner Project Planner, Fall 2007}

\section{CONTENT AND SUPPORTING DETAILS}

Describe the content (what is this project "about"?) and other pertinent project details not discussed below.

\section{GENRE/FORMAT}

Describe the form (NOT the content) of the document you want students to produce. (Do you envision a brochure, a report, a map with accompanying narrative, a Web page, or ...?) Why have you chosen this format for this project? Where might students see useful examples of this kind of document? How do you want the finished project to "look"? That is, what kind of impression do you want to create (slick, accessible, scholarly, etc.)? How many pages or what size should the finished product be?

\section{SITUATION}

Explain how this project supports your organization's goals and research efforts. Describe the project's consequences for the broader mission it supports.

Define and describe the audience for which this document is intended. What is the document's purpose? That is, what response is it intended to elicit from its audience? (What do you want the audience to think or do after encountering this writing?)

\section{USEFUL TIPS}

Offer advice on gathering data, conducting an analysis, developing, framing, designing, and/or shaping the product.

\section{SUGGESTED TEMPLATE OR SAMPLE DOCUMENTS}

Please identify a particularly good example of a similar project you can share with your students. The example should illustrate the standard you expect this project to meet.

\section{READINGS/RESOURCES}

What material (articles, book s, Web sites, videos, etc.) can your organization provide or recommend to prepare students to work on this project? 


\section{EVALUATION CRITERIA}

What elements do you think should contribute to assessing this project? Please list the criteria you think the instructor should apply to evaluation. If this project were done by a staff member, on what basis would you evaluate its worth to your organization? 


\section{APPENDIX 2}

\section{CCLCP Writing Projects for English 160 and}

English 122, Fall 2007

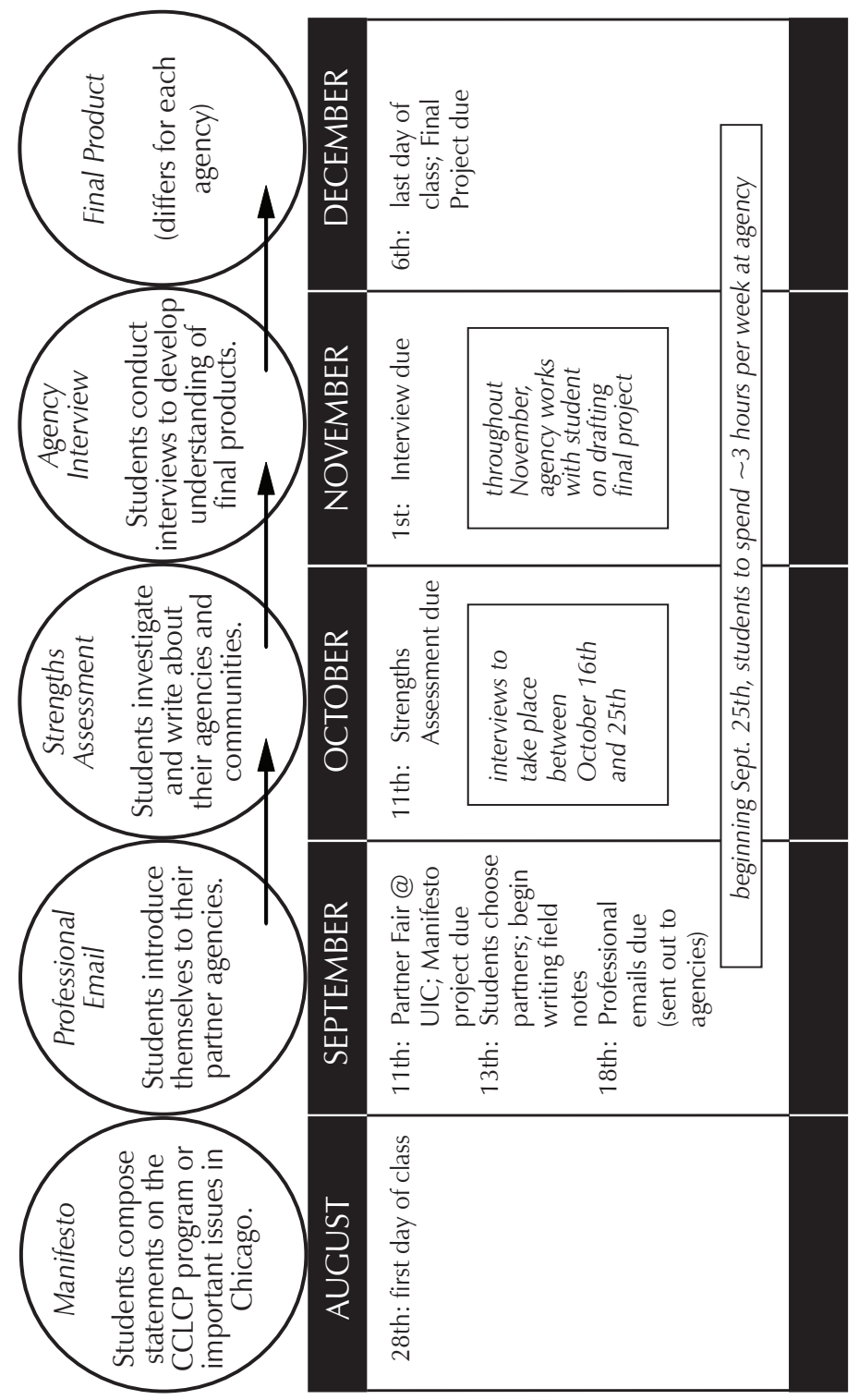




\title{
APPENDIX 3
}

\section{CCLCP Partner Project Planner}

\section{Jane Addams Hull-House Museum (JAHHM) Immigrants' Guide to Chicago Project}

\author{
Margot Nikitas, Hull-House \\ Caroline Gottschalk-Druschke, CCLCP \\ Carla Navoa, Student
}

\section{CONTENT AND SUPPORTING DETAILS}

Describe the content (what is this project "about"?) and other pertinent project details not discussed below.

The final project will promote JAHHM's immigrants' guide to Chicago project, fully described below:

The Jane Addams Hull-House Museum is creating a comprehensive immigrants' resource guide to Chicago. Written by and for immigrants, Chicago: An Immigrant City will compile critical information for both documented and undocumented immigrants on how to obtain basic goods and services. The book will also emphasize solidarity building, social entrepreneurship, and how new immigrants can develop and build cultural capital in our diverse city by accessing arts and culture in Chicago's many public spaces. These include community centers, galleries, schools, public events, and all of Chicago's major cultural institutions.

Since its founding by Jane Addams and Ellen Gates Starr in 1889, Hull-House served as a vital community center for its immigrant neighbors. Hull-House offered citizenship and English classes, developed innovative programs in the visual and performing arts, provided space for social gatherings and celebrations, and advocated for the rights of immigrants, workers, and women. Drawing on Hull-House's tradition of emphasizing arts programming to promote a more participatory democracy, the book will feature an in-depth guide to arts and culture in Chicago. Here immigrants will learn about Chicago's wealth of museums, historic sites, ethnic fairs and festivals, music venues, public gardens and parks, theaters, and more. 
One of the most unique aspects of Chicago: An Immigrant City will be a chapter on Chicago's immigrant youth culture, written by young people from immigrant communities across the city. These young writers will incorporate different creative media such as spoken word, poetry, and visual artwork to reflect on and grapple with the immigrant experience. The writing process will also provide an opportunity for intergenerational dialogue in immigrant families.

In addition to a convenient directory of service organizations and information about basic needs such as housing, childcare, employment, legal aid, and medical care, Chicago: An Immigrant City will also include sections on legal rights and the justice system-featuring a detachable "Know Your Rights" card; Chicago's diverse media; educational institutions; and how immigrants can get locally involved in the struggle for a more just society.

Chicago: An Immigrant City is currently slated to be published in one volume in English, Spanish, Polish, and Chinese in order to serve Chicago's fastest-growing immigrant communities. Chicago-based immigrant organizations including Heartland Alliance's National Immigrant Justice Center-the direct legacy organization of Hull-House's Immigrants' Protective League-Korean American Resource and Cultural Center, Chinese Mutual Aid Association, United African Organization, El Zócalo Urbano, and Polish American Association have already joined on as partners and consultants.

\section{GENRE/FORMAT}

Describe the form (NOT the content) of the document you want students to produce. (Do you envision a brochure, a report, a map with accompanying narrative, a Web page, or ... ?) Why have you chosen this format for this project? Where might students see useful examples of this kind of document? How do you want the finished project to "look"? That is, what kind of impression do you want to create (slick, accessible, scholarly, etc.)? How many pages or what size should the finished product be?

The form of this document will be a flyer/program-or text within a flyer/program-about the immigrants' guide project for the Jane Addams Day promotional materials. This flyer will be designed to look consistent with other Museum publicity materials. Carla will be responsible for the text, NOT the design that will be on the flyer/program. Carla will have access to examples of the Museum's previous/existing promotional flyers/programs to get an idea of the form, style, and tone 
the text should have. The size of the finished text will be approximately 250-500 words. Carla will also assist with choosing appropriate images for the flyer/program.

\section{SITUATION}

Explain how this project supports your organization's goals and research efforts. Describe the project's consequences for the broader mission it supports.

Define and describe the audience for which this document is intended. What is the document's purpose? That is, what response is it intended to elicit from its audience? (What do you want the audience to think or do after encountering this writing?)

This project will be promotional materials for Chicago: An Immigrant City, which is a project of JAHHM to create a comprehensive immigrants' resource guide to Chicago. This resource guide will continue the legacy of the Hull-House Settlement's commitment to supporting immigrants' rights and aiding their transition to American, urban society. Specifically, this promotional text will appear on a flyer/program for the Museum's Jane Addams Day celebrations on December 9-10, 2007. Officially, Jane Addams Day is December 10, the day on which she received the Nobel Peace Prize in 1931.

The audience for which this document is intended is the general public, JAHHM visitors, and visitors who attend the Jane Addams Day celebrations on December 9-10, 2007. The text on the flyer/program will connect the immigrants' guide project to Hull-House history and Jane Addams's vision of peace as not merely an international concern but as actively fostering the conditions for peace to flourish in local neighborhoods and communities.

\section{USEFUL TIPS}

Offer advice on gathering data, conducting an analysis, developing, framing, designing, and/or shaping the product.

Carla should look at previous examples of JAHHM promotional materials to get an idea of the tone and style of the text. Carla will also need to be familiar with existing publicity text on the immigrants' guide project. In order to make a successful and accurate link to HullHouse history, Carla will need to read articles/books to which I will direct her. 


\section{SUGGESTED TEMPLATE OR SAMPLE DOCUMENTS}

Please identify a particularly good example of a similar project you can share with your students. The example should illustrate the standard you expect this project to meet.

See above.

\section{READINGS/RESOURCES}

What material (articles, books, Web sites, videos, etc.) can your organization provide or recommend to prepare students to work on this project?

News about current immigration debate: Chicago immigrant/ethnic history and Chicago's current demographics; Books by and about Jane Addams and Hull-House (available at JAHHM's resource library and the Richard J. Daley Library); www.hullhousemuseum.org and www.uic. edu/jaddams/hull/urbanexp/; New York Times Guide for Immigrants to New York City (as an example of an immigrants' guide but NOT as a direct model for the guide JAHHM will create); Existing text about the immigrants' guide used for promotional materials.

\section{EVALUATION CRITERIA}

What elements do you think should contribute to assessing this project? Please list the criteria you think the instructor should apply to evaluation. If this project were done by a staff member, on what basis would you evaluate its worth to your organization?

This project will be evaluated for: grammar, usage, choice of language, style, tone, accuracy of content, creativity, etc. 